\title{
EXPERIMENTAL STUDY AND APPLICATION IN STEEL STRUCTURE OF 'DUAL FUNCTIONS' METALLIC DAMPER
}

\author{
Gang $\mathrm{Li}^{1{ }^{1 *}}$ and Hong-Nan $\mathrm{Li}^{2}$ \\ ${ }^{1}$ Associate Professor, Faculty of Infrastructure Engineering, Dalian University of Technology, \\ Dalian, Liaoning Province, China \\ ${ }^{2}$ Professor, Faculty of Infrastructure Engineering, Dalian University of Technology, \\ Dalian, Liaoning Province, China \\ *(Corresponding author: E-mail: gli@dlut.edu.cn)
}

Received: 20 June 2012; Revised: 5 November 2012; Accepted: 26 November 2012

\begin{abstract}
A new type of metallic damper is presented in this study. It is so-called as "dual functions" metallic damper, since it has two characteristics of high initial stiffness and good energy-dissipating capability. Its initial stiffness is increased through making it bearing exterior in-plane force, and its energy-dissipating capability is improved through making it different shapes. Quasi-static tests with scale and full-scale models of the metallic dampers specimens designed with above idea are carried out, respectively. Two outstanding metallic dampers named round-hole metallic damper (RHMD) and double X-shaped metallic damper (DXMD) were selected and the DXMD was applied in an actual steel structure to improve initial stiffness of original structure under normal use or frequency earthquake and to dissipate inputting energy during great earthquakes. In addition, a three-dimensional model was established using finite element software and dynamic response comparison of the steel structure with and without DXMDs was conducted. The results shown that the metallic dampers presented here not only provide certain stiffness in the normal application, but also are of good ability of energy dissipation.
\end{abstract}

Keywords: Steel structure, metallic damper, hysteresis loop, seismic response

\section{INTRODUCTION}

Earthquake can make structures damaged and crumble. The traditional approach to seismic design has been based upon providing a combination of strength and ductility to resist the imposed loads. Thus, the level of the structural security cannot be achieved, because the disadvantage of the designing method is lack of adjusting capability subjected to an uncertain earthquake. Presence of some damping (energy dissipation) in buildings has been recognized and developed by most professional researchers (Lackner and Rotea [1]; Housner et al. [2]; Li [3]; Tanaka [4]). Passive energy-dissipating system, as a vibration control method, leads inputting energy from earthquake to special elements, thereby reduces energy-dissipating demand on primary structural members and minimizes possible structural damage.

The inelastic deformation of metallic is an effective mechanism for input earthquake energy dissipation. In addition, metallic is also a popular and inexpensive choice for an energy dissipation device because of its relatively good ductility and high potential for dissipating energy in the post-yield region. The idea of utilizing separate metallic dampers in the structures to absorb a large portion of the seismic energy began with the conceptual and experimental work by Kelly [5]. Then, numerous of various types of energy-absorbed metallic devices have been proposed, i.e. X-shaped and triangular plate metallic dampers (Whittaker [6]; Tsai [7]). After a series of theoretical and experimental researches, more and more interests and attentions are turned on the application of metallic dampers in the actual projects (Skinner [8]; Martinesz-Romero [9]; Bartera [10]; Mualla [11]; Min [12]; Phocas [13]) and much researches about the structure with passive dissipation devices were carried out (Lin [14]; Singh [15]; Soong [16]; Tehranizadeh [17]; Zhang [18]). Ordinary metallic damper is dependent on its out-of-plane bending deformation so that provide additional damping for the structures, even to reduce dynamic response of the structures subjected to the environmental loadings (Moreschi [19]; Curadelli [20]). The advantage of this deformation 
mechanics is uniform distribution along the full height of the steel plate. However, inelastic deformation of conventional metallic damper probably occurs when it is subjected to a relatively small disturbance (wind or earthquake), since its out-of-plane stiffness is relatively low. As a result, it has to be replaced after the disturbance.

In this paper, the stiffness of the metallic damper is increased through making it bearing exterior in-plane force, and unfavorable deformation capability is solved through changing metallic plate shape. The metallic damper designed with above-mentioned idea is named "dual functions" metallic damper, because it not only provides certain stiffness in normal use for a building, but also are of good ability of the seismic energy-dissipation. Tests for scale and full-scale models of the "dual functions" metallic damper were conducted and two outstanding metallic dampers were selected and one of them applied in an actual steel structure. Numerical analysis results show the effectiveness of this type of metallic damper.

\section{QUASI-STATIC TEST FOR SCALE MODELS}

Although the initial stiffness of steel plate can be improved greatly when it is subjected to an imposed force in its own plane, it limits shearing deformation capability. This problem can be solved through following two ways: low yield strength steel plate selection and making steel plate reasonable geometrical shape. In this section, four various metallic dampers specimens made of 4 mm thickness steel plates were produced and the quasi-static tests for the scale models were conducted. The yield stress of the steel plate is $235 \mathrm{Mpa}$. The test setup is shown in Figure 1 . The objective of the scale test is to choose outstanding metallic damper with the best deformation capability and excellent energy-dissipating capability from them. These four metallic dampers have the same boundary dimension size. The criterion about damper selection is mainly based on their own hysteretic loops curves and performance observed during the tests. Each metallic damper is subjected to repeated cyclic loadings. These metallic dampers were regarded as disable as soon as the bearing strength decreasing exceeds $25 \%$ or obvious crack appears on its surface. Hysteretic relation of the cyclic loads and the displacement is discussed as follows :

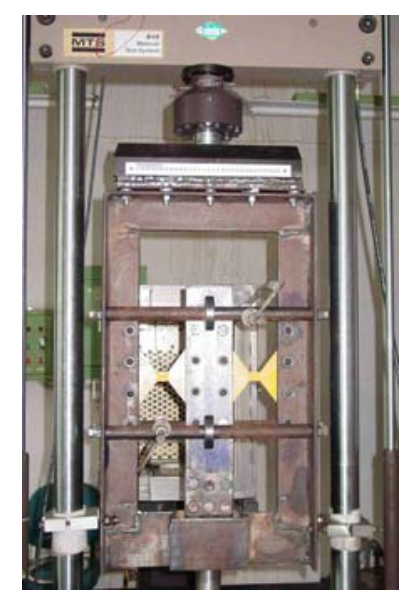

Figure 1. Test Setup for Scaled Models

\subsection{X-shaped Metallic Damper (XMD)}

A photograph and geometric sketch of the X-shaped metallic damper and its hysteretic loop curve are shown in Figure 2(a), 2(b) and 2(c). It was observed from Figure 2(b) that the X-shaped metallic damper has larger initial stiffness and higher yield strength. However, pinching phenomena found in the hysteretic loop curve shows that the X-shaped metallic damper is unable to provide 
stable working performance. The reason is sourced from the stress concentrations at steel plate corners. The hysteretic loop curve and deformation process during test indicated that the X-shaped damper is not an effective energy-dissipating device, because it is lack of enough deformation and energy dissipation capability.

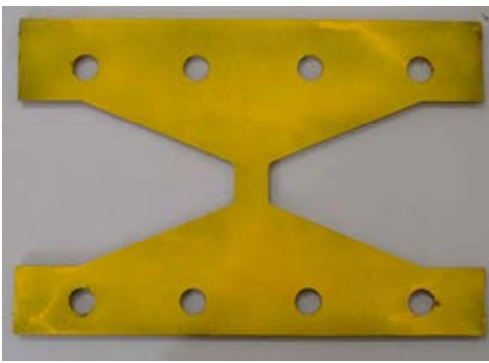

(a)

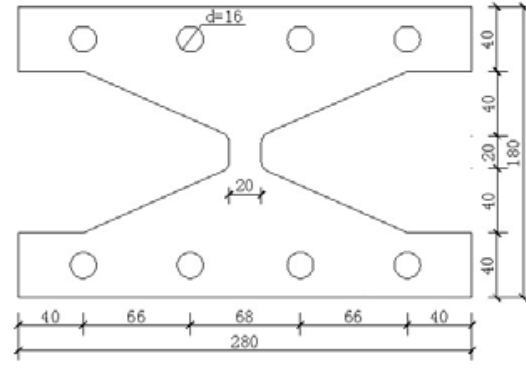

(b)

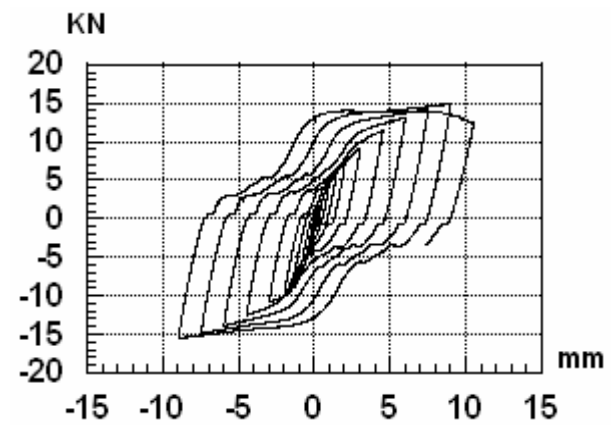

(c)

Figure 2. The Photograph, Geometric Sketch and Hysteretic Loop Curve of the XMD: (a) the Photograph; (b) Geometric Sketch (mm); (c) Hysteretic Curve

\section{$2.2 \quad$ Strip Metallic Damper (SMD)}

A photograph and geometric sketch of the metallic damper called as strip metallic damper and its hysteretic curve are shown in Figure 3(a), 3(b) and 3(c). The hysteretic curve reflects that the strip metallic damper has large initial stiffness, good deformation capability and energy-dissipating capability. However, an abrupt bearing strength reduction was observed due to out-of-plane buckling in strip region. Therefore, the large buckling deformation of whole damper probably appeared under slightly vertical load. Although the strip metallic damper exhibits good energy-dissipating capability and high initial stiffness, it is lack of enough stability while subjected to vertical load.
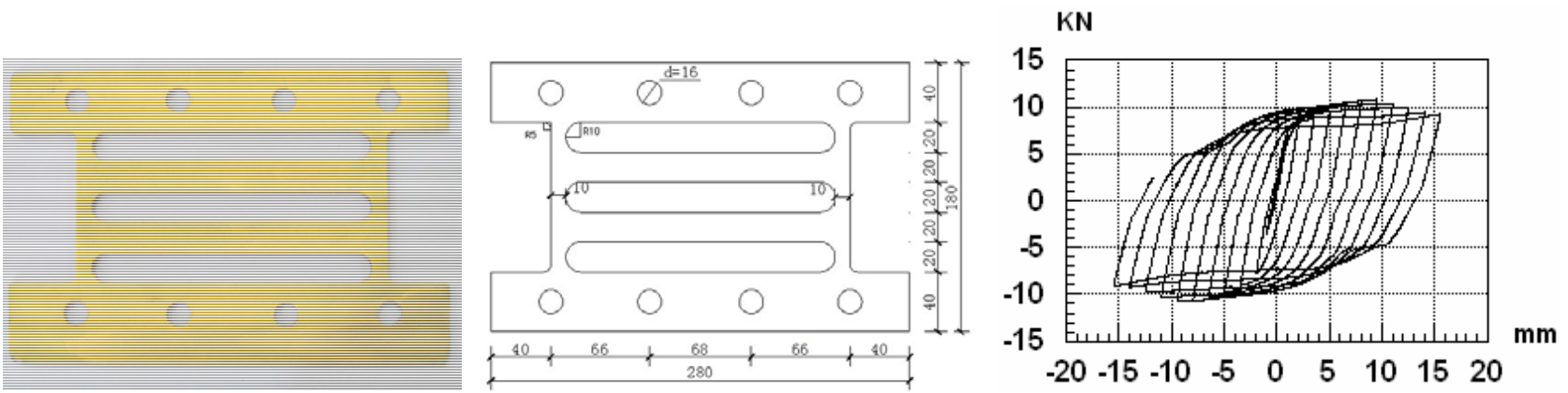

Figure 3. The Photograph, Geometric Sketch and Hysteretic Loop Curve of the SMD: (a) the Photograph; (b) Geometric Sketch (mm); (c) Hysteretic Curve

\section{$2.3 \quad$ Round-hole Metallic Damper (RHMD)}

A photograph and geometric sketch of the RHMD and its hysteretic curve are shown in Figure 4(a), 4(b) and 4(c). Stable hysteretic feature of the RHMD was observed during overall test process. The hysteretic loop curve revealed that the RHMD not only has large initial stiffness, but also is of excellent energy-dissipating capability. It is an outstanding and effective energy-dissipating device. 

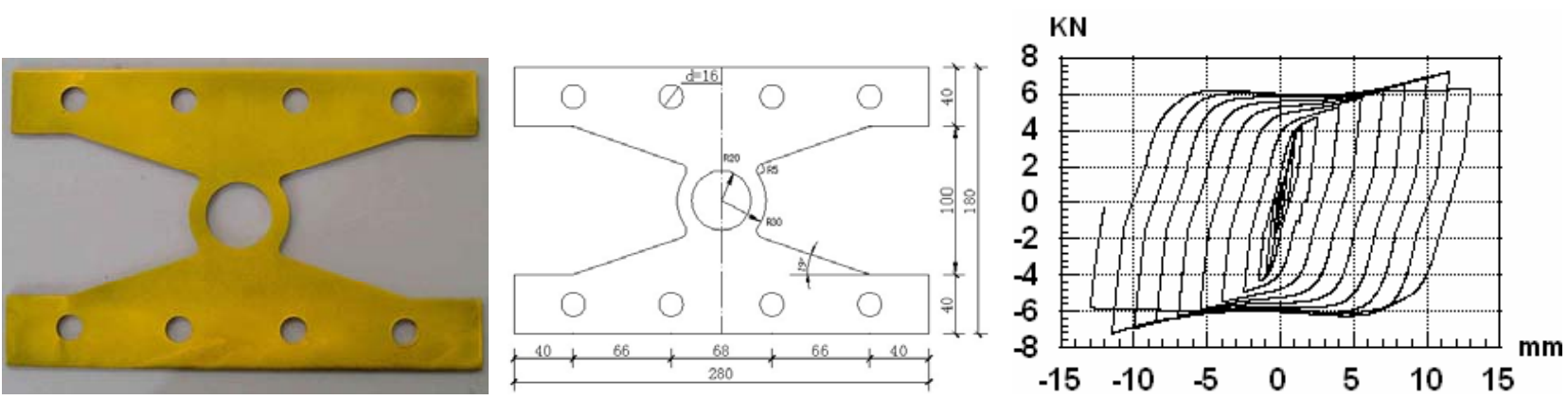

Figure 4. The Photograph, Geometric Sketch and Hysteretic Loop Curve of the RHMD: (a) the Photograph; (b) Geometric Sketch (mm); (c) Hysteretic Curve

\subsection{Double X-shaped Metallic Damper (DXMD)}

A photograph and geometric sketch of the DXMD and its hysteretic curve are illustrated in Figure 5(a) and 5(b). The buckling problem of the strip metallic damper described in section 2.2 is solved by making steel plate double X shape. The DXMD exhibits more stable hysteretic performance than the strip metallic damper. Hysteretic loop curve shows that the DXMD has both large initial stiffness and energy dissipating capability.
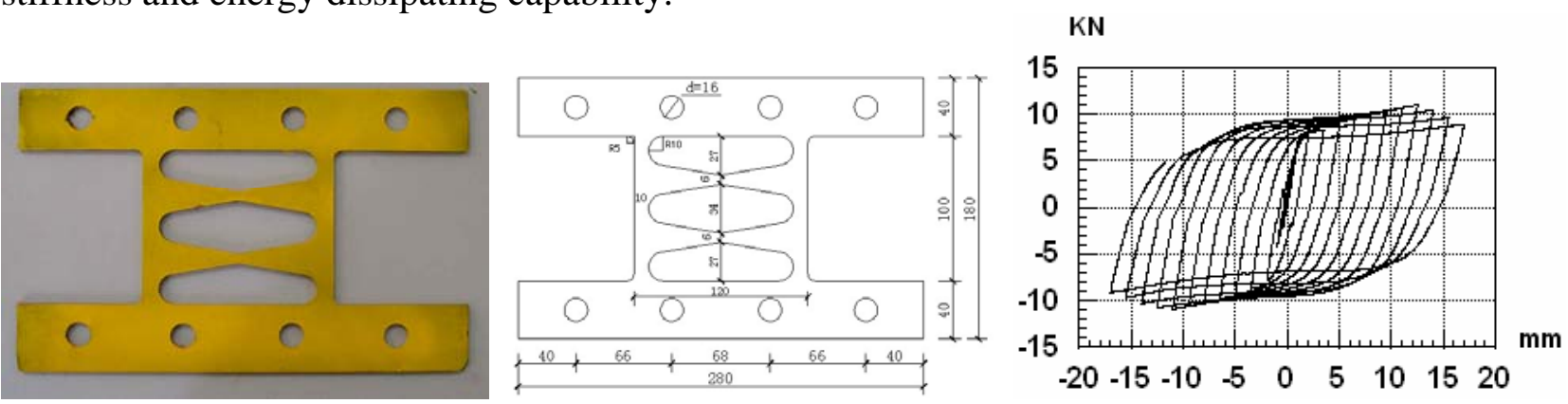

Figure 5. The Photograph, Geometric Sketch and Hysteretic Loop Curve of the DXMD: (a) the Photograph; (b) Geometric Sketch (mm); (c) Hysteretic Curve

On the basis of the above-presented results, the RHMD and the DXMD are better than others on energy-dissipating capability. Full-scale model test, numerical simulation and application in actual building below will focus on these two outstanding metallic dampers.

\section{QUASI-STATIC TEST FOR FULL-SCALE MODELS}

\subsection{Test for Full Scale Models}

Full-scale models of the RHMD and the DXMD were designed and product. These two types of metallic dampers are made of $50 \mathrm{~mm}$ thickness steel plate. The plane dimensions of these two dampers are shown in Figure 6. The test setup is shown in Figure 7. 


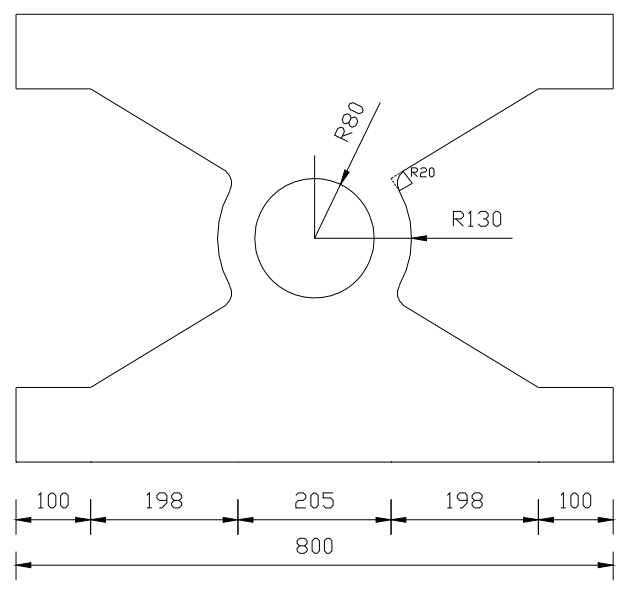

(a)
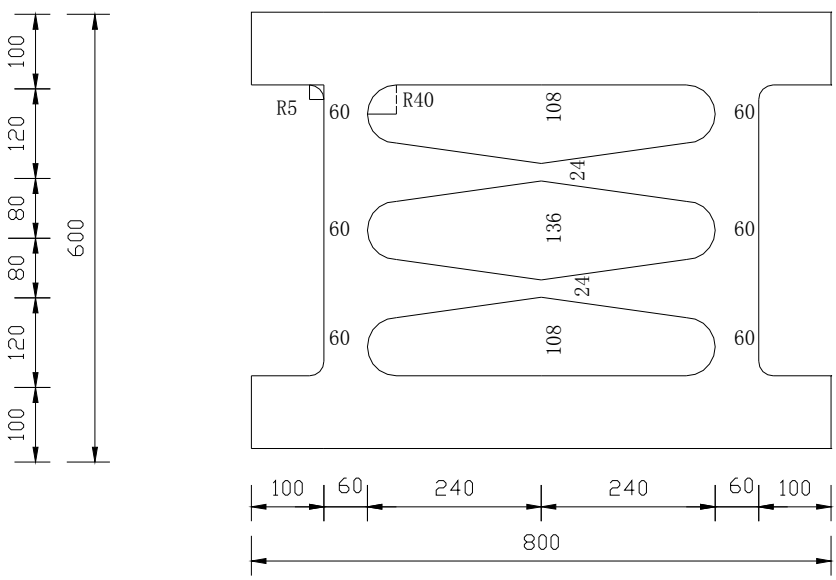

(b)

Figure 6. Plane Dimension of Full-scale Models: (a) RHMD; (b) DXSD (mm)

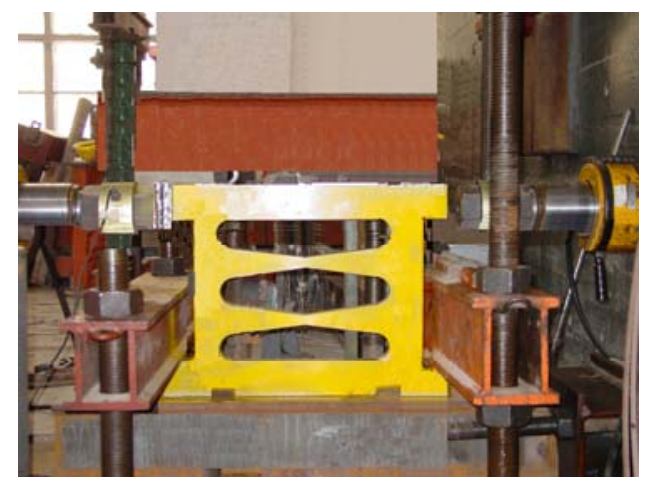

Figure 7. Test Setup for Full-scale Models

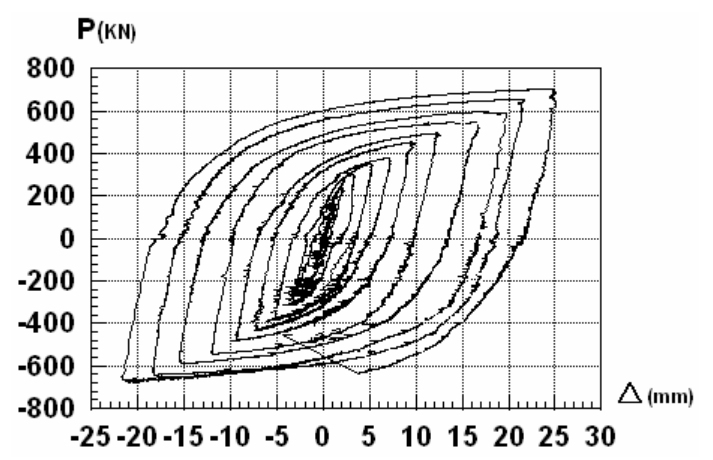

(a)

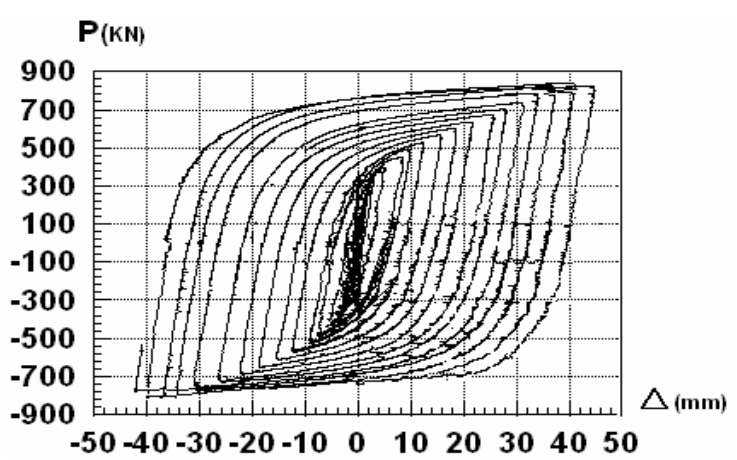

(b)

Figure 8. Hysteretic Curve of the Full-scale Model: (a) RHMD; (b) DXMD

Figures 8(a) and 8(b) show hysteretic curve of full-scale models of the RHMD and the DXMD. It was observed from these figures that these two metallic dampers have the same stable hysteretic behaviors and good energy-dissipating capability as the scale models and are suitable for application in actual structure. In addition, several key parameters of these two full-scale models were defined as: elastic lateral stiffness of the RHMD $K_{d l}=171 \mathrm{kN} / \mathrm{mm}$ and its yielding strength $P_{y 1}=375 \mathrm{kN}$; elastic lateral stiffness of the DXMD $K_{d 2}=102.5 \mathrm{kN} / \mathrm{mm}$ and its yielding strength $P_{y 2}=410 \mathrm{kN}$. 


\subsection{Numerical Simulation}

Finite element models of the DXMD and the RHMD for simulating full-scale models test process were established using software ANSYS. Stress distributions and hysteretic loops of these two metallic dampers are shown in Figures 9 and 10. It can be seen from Figures 10(a) and 10(b) that the numerical simulation results agree well with the experimental data. Although experimental results exhibit slightly differences, they can represent true behavior of these two kinds of metallic dampers under cyclic loadings.

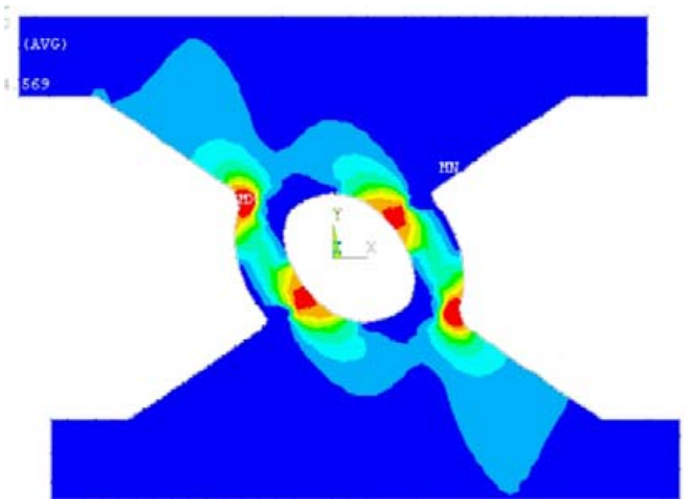

(a)

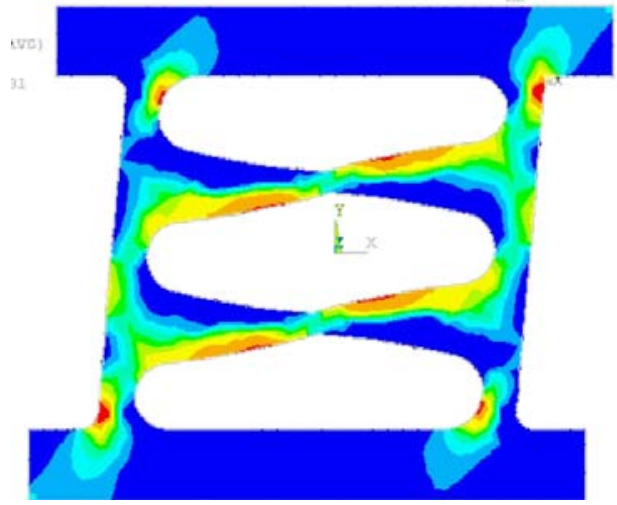

(b)

Figure 9. Stress Distribution of the Full-scale Model: (a) RHMD; (b) DXMD

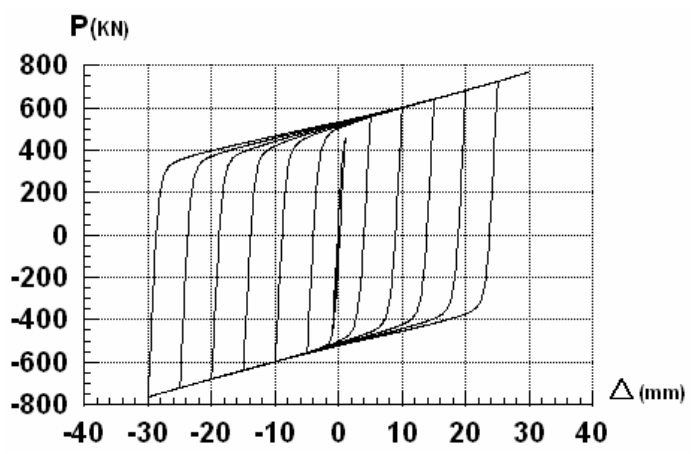

(a)

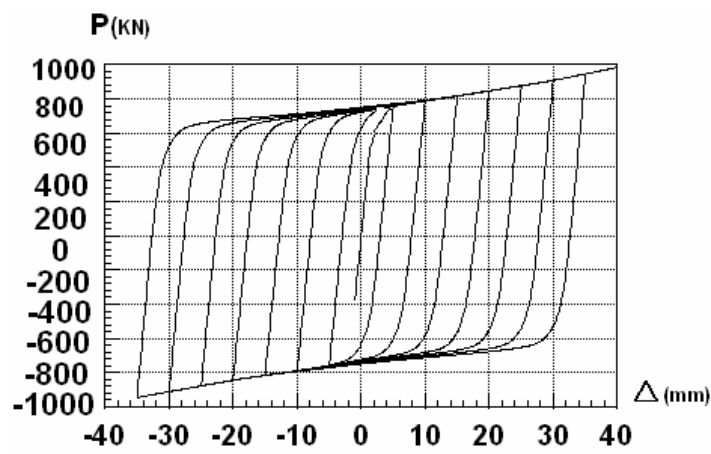

(b)

Figure 10. Numerical Hysteretic Curve of the Full-scale Mode: (a) RHMD; (b) DXMD

\section{APPLICATION IN AN ACUTUAL STEEL STRUCTURE}

\subsection{Description of the Steel Structure}

A steel structure with eight stories shown in Figure 11 is located in China. The sketch of this structure is depicted in Figure 12. The columns in the frame are square steel tubes and $\mathrm{H}$ type steel and the beams are $\mathrm{H}$ type steel. The DXMDs are installed on the each floor of the steel structure due to overall weak stiffness of this structure in $Y$ direction. The seismic protection intensity of the steel structure is degree VII, and the site soil belongs to the type $\Pi$ (medium hard soil) based on the China Seismic Code [21]. Two matched earthquakes acceleration records shown in Table 1 are selected according to the site where the structure is located. Two acceleration records, which peak are adjusted to $220 \mathrm{~cm} / \mathrm{s}^{2}$ are inputted in two dimensions of the steel structure, i.e. $X$ and $Y$ directions. 
Table 1. Earthquake Records

\begin{tabular}{cccc}
\hline Serial number & Station & Earthquake & Components \\
\hline \multirow{2}{*}{1} & 0453 Taft Lincoln & Kern County & Taf021(Y) \\
& School & $(21 / 7 / 1952)$ & TAF111(X) \\
\hline \multirow{2}{*}{2} & LA - BALDWIN & Northridge & BLD090(Y) \\
& HILLS & $(17 / 1 / 1994)$ & BLD360(X) \\
\hline
\end{tabular}

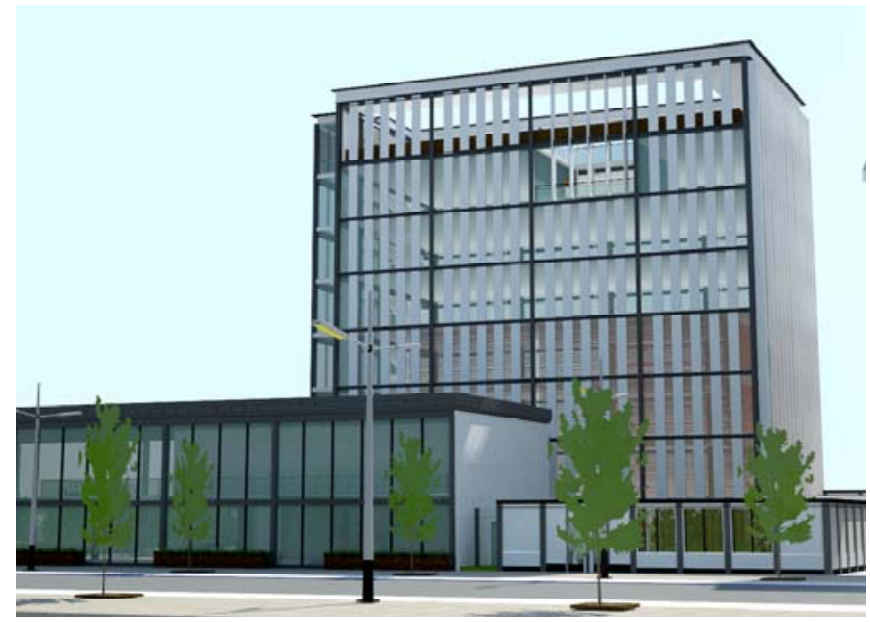

Figure 11. The Sketch of the Steel Structure
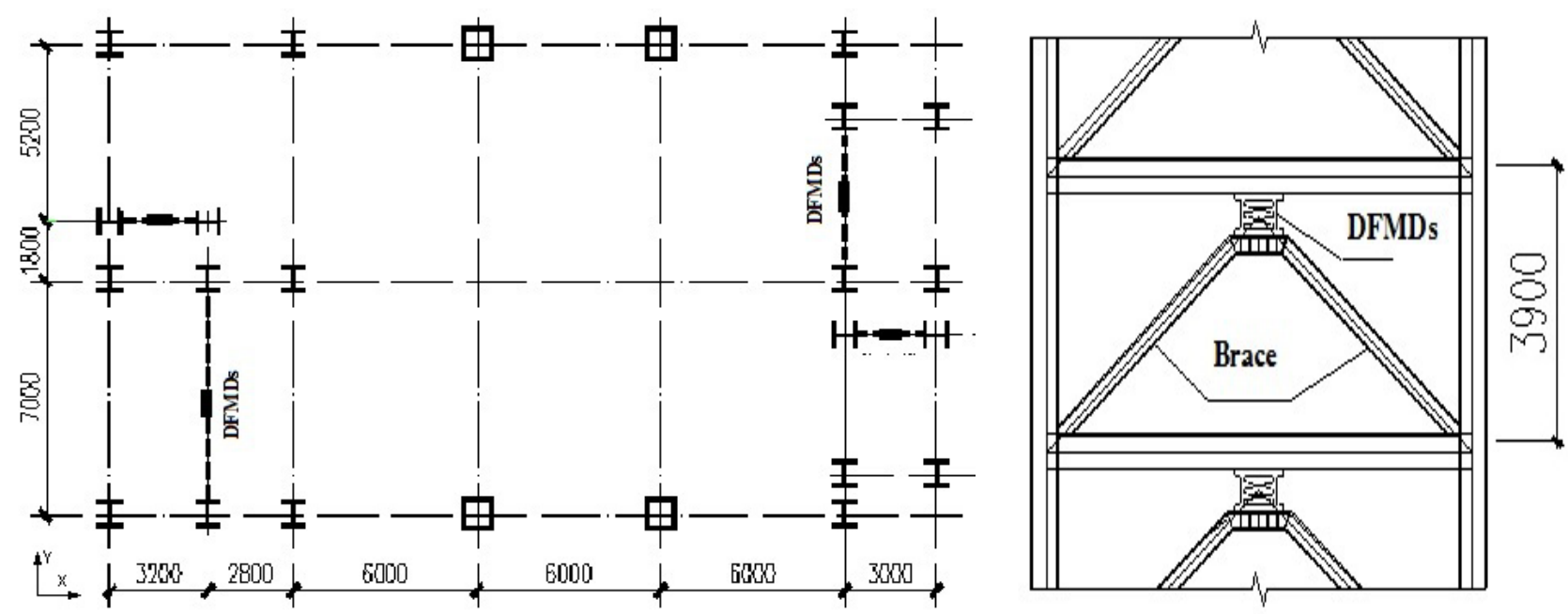

Figure 12. Plane and Elevation Sketch

The DXMDs are fixed on the cross-points of the beams and the braces. Its upper side is connected to the beams and its underside is attached with the braces. Installation position of the DXMD was shown in Figure 13. 


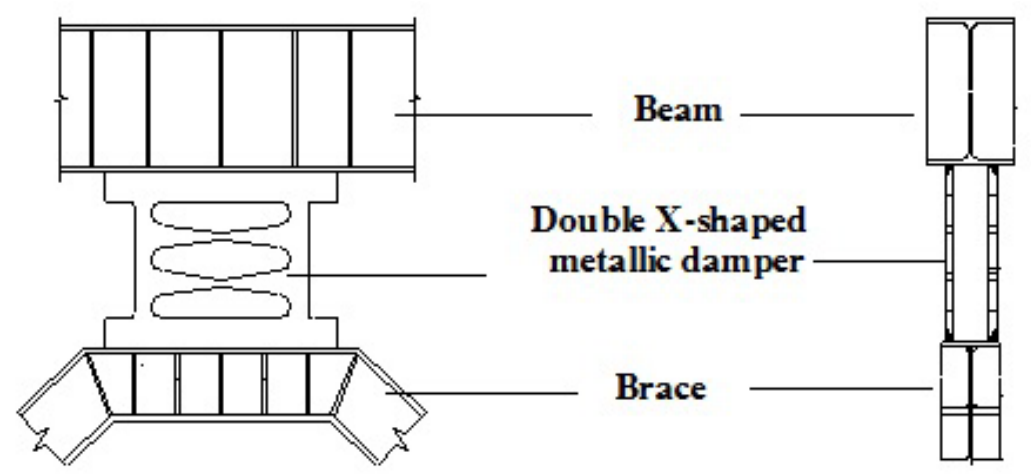

Figure 13. Installation of the DXMD

\subsection{Establishment of Finite Element Model}

To obtain more exact structural story-drifts and evaluate the DXMDs effectiveness on the structural vibration reduction, a three-dimensional frame model is established with ADPL language in the ANSYS program. BEAM188 in the ANSYS program is usually used to model beams and columns according to the Timoshenko's beam theory which apply a linear or a quadratic three-dimensional beam element. Material properties for beams, braces and columns are $E=2.1 \mathrm{GPa}$ and $\sigma_{y}=345$ MPa. Overall finite element model is shown in Figure 14 and detailed configuration about the DFMDs connecting with beam and brace is illustrated in Figure 15. In the solution of structural dynamics equation, the Rayleigh damping method is used and the damping ratio of 0.4 is selected here due to considering plastic behavior of the steel structure.

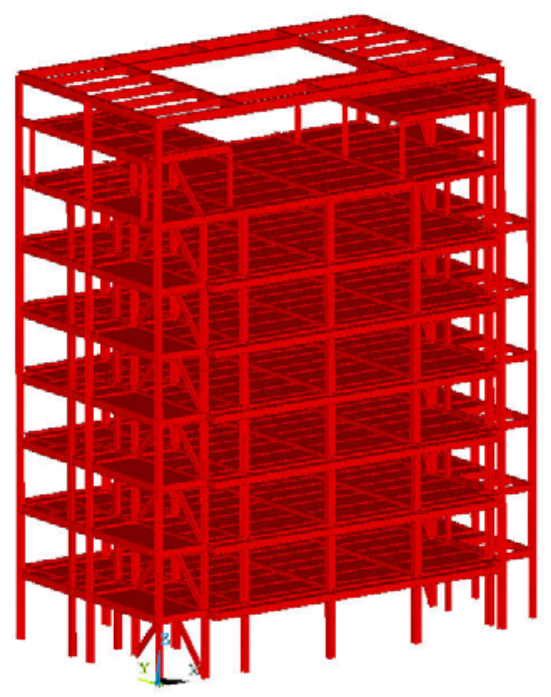

Figure 14. Overall Finite Element Model

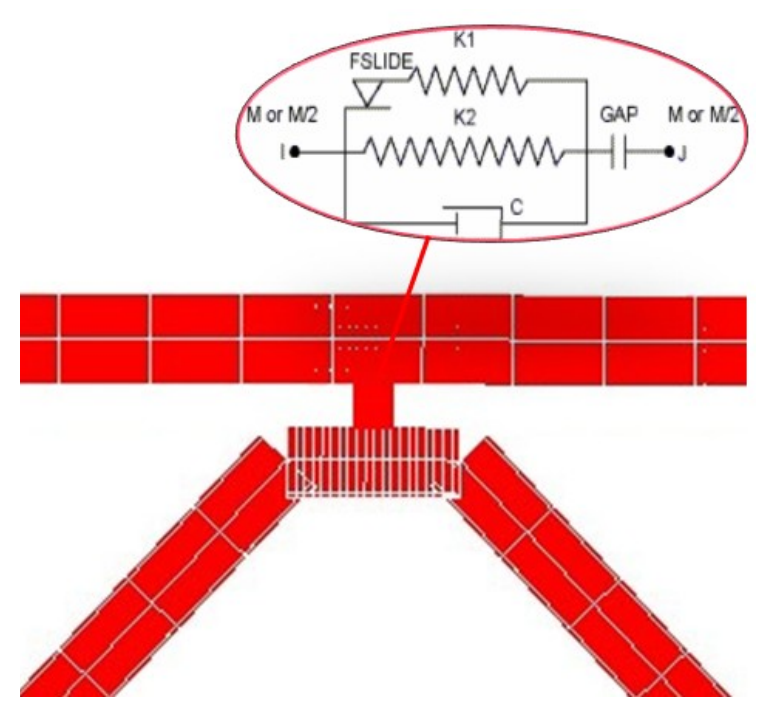

Figure 15. Finite Element Model of the Local Connection

\subsection{Modal Analysis}

As an important step of numerical simulation, the natural frequencies and modal shapes of the structures are used to identify its elastic property. The first three natural periods calculated by the ANSYS are listed in Table 2, and corresponding modal shapes are shown in Figures 16 and 17. It was observed that the natural periods of the steel structure with the DXMDs are obviously smaller than that without the DXMDs, because assemble of the steel braces and DXMDs provide additional stiffness to the original steel structure. Figures 16 and 17 also show that the basic modal shapes of the steel structure with the DXMDs is close to that of without DXMDs because of the symmetrical arrangement of the DXMDS. 
Table 2. Natural Periods Calculated by ANSYS (Unit: second)

\begin{tabular}{cccc}
\hline Structures & $1^{\text {st }}$ period & $2^{\text {st }}$ period & $3^{\text {st }}$ period \\
\hline Structure without DXMDS & 1.98 & 1.81 & 1.49 \\
Structure with DXMDs & 1.77 & 1.29 & 1.13 \\
\hline
\end{tabular}

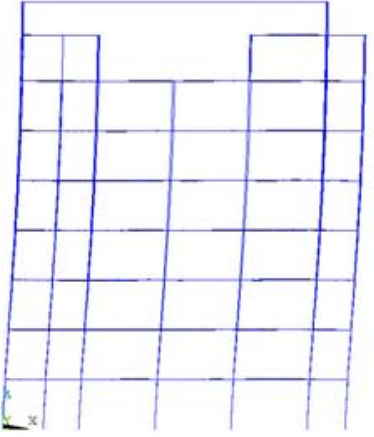

(a)

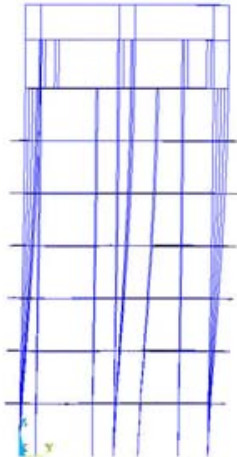

(b)

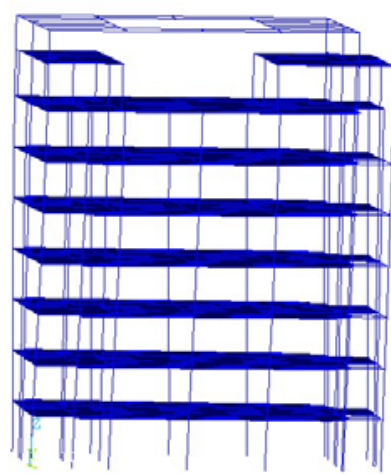

(c)

Figure 16. First Three Modes of the Structure without DXMDs: (a) $1^{\text {st }}$ Modal Vibration; (b) $2^{\text {nd }}$ Modal Vibration; (c) $3^{\text {th }}$ Modal Vibration

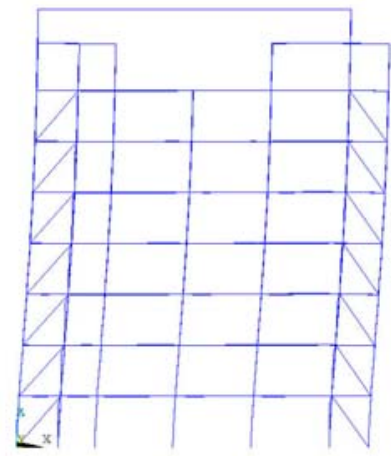

(a)

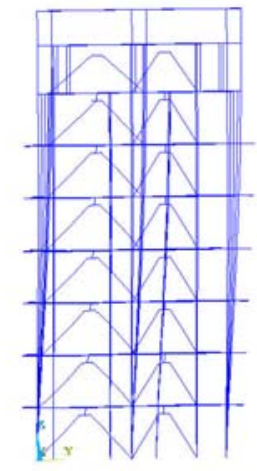

(b)

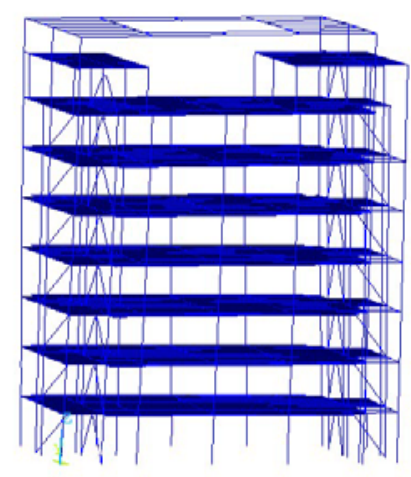

(c)

Figure 17. First Three Modes of the Structure with DXMDs: (a) $1^{\text {st }}$ modal vibration;

(b) $2^{\text {nd }}$ Modal Vibration; (c) $3^{\text {th }}$ Modal Vibration

\subsection{Dynamical Response Results}

Displacement and acceleration responses of the steel structures with and without the DXMDs shown in Figures 18 (a) to 18(d) were plotted together for validating the DXMDs effectiveness.

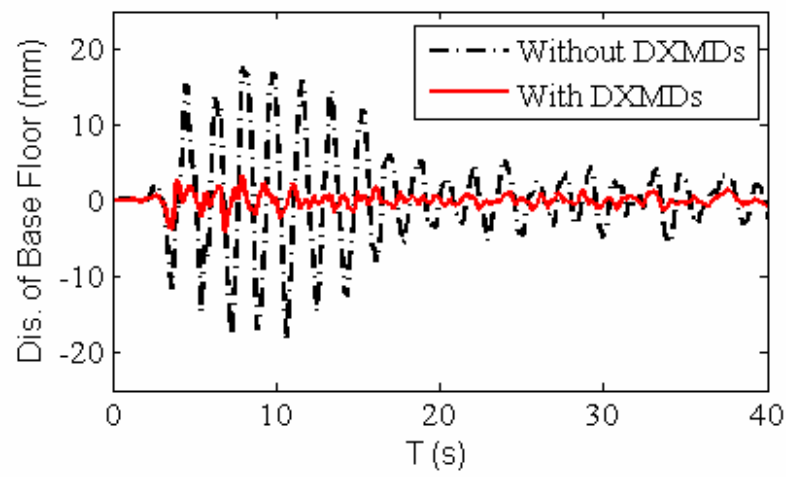

(a)

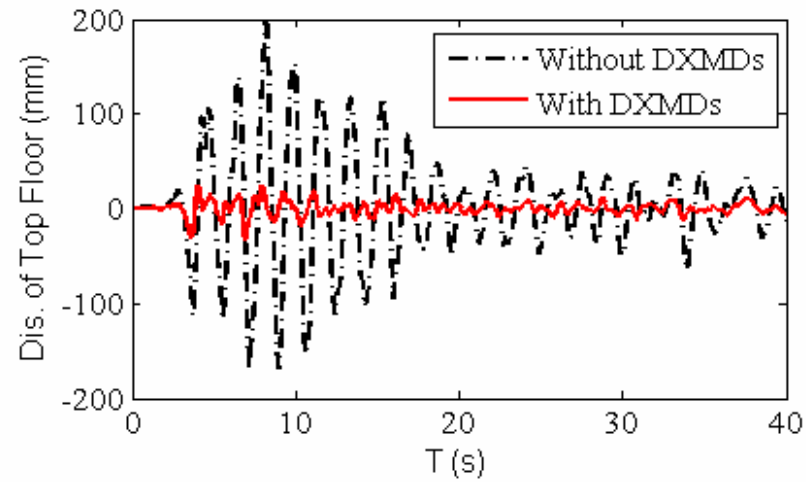

(b) 


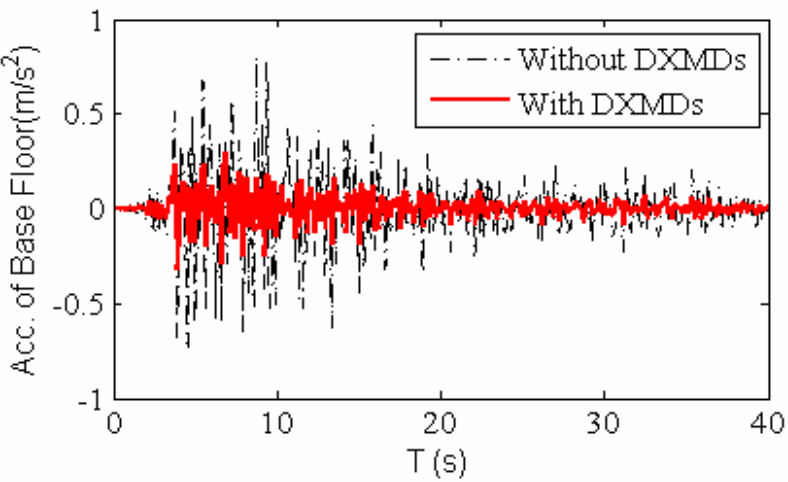

(c)

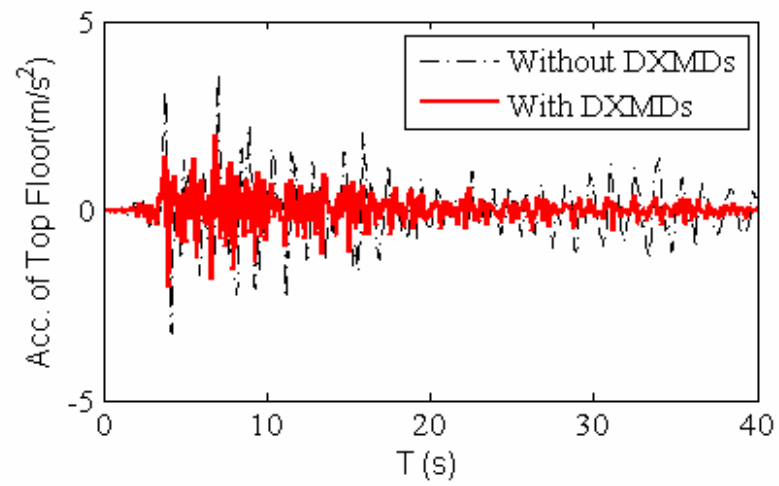

(d)

Figure 18. Displacement Response of the Structure with and without DFMDs under 1\# record: (a)

Base Floor; (b) Top Floor

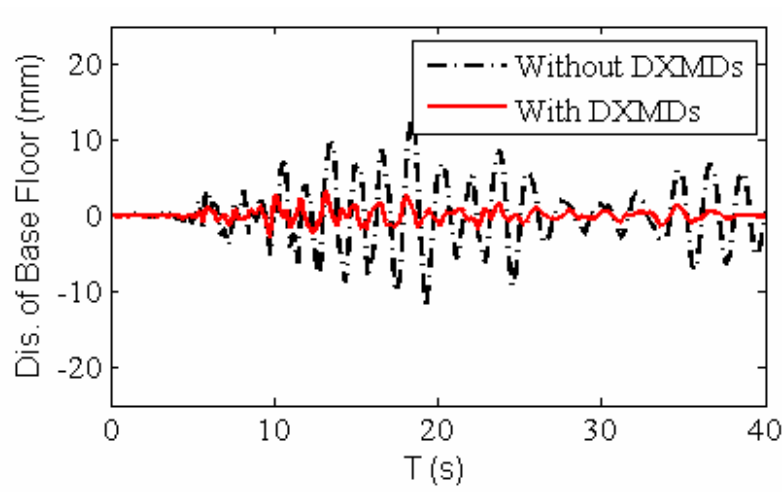

(a)

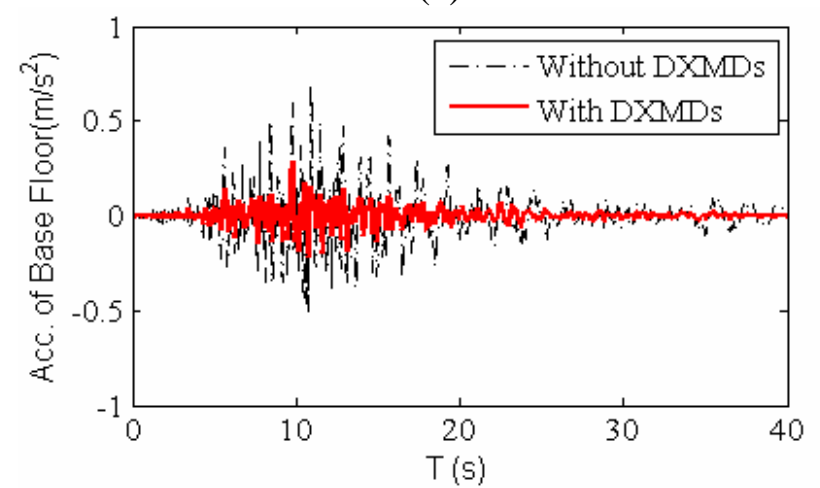

(c)

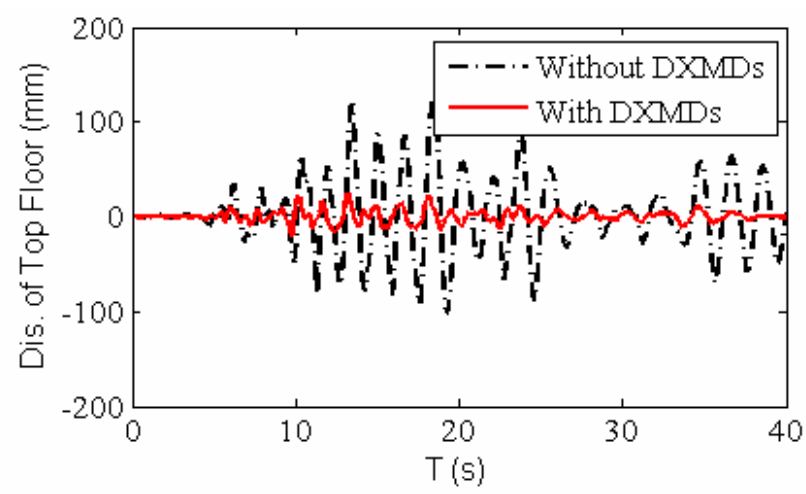

(b)

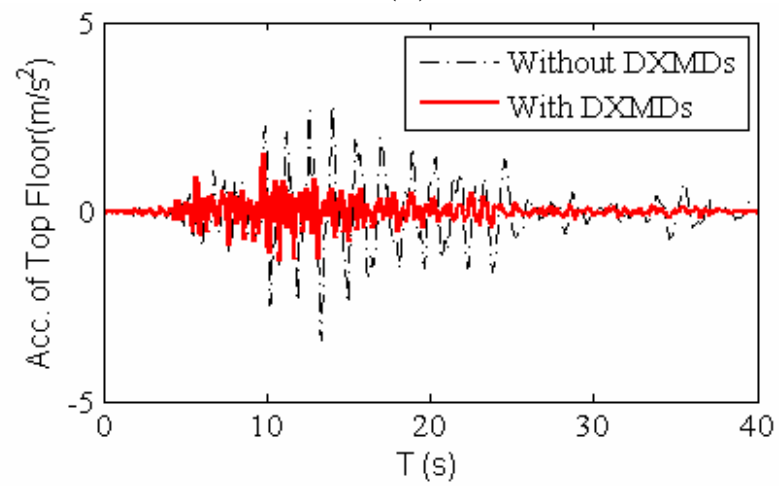

(d)

Figure 19. Displacement Response of the Structure with and without DFMDs under 2\# Record:

(a) Base Floor; (b) Top Floor

It can also be seen from Figure 18(a) that peak displacement at the base of the steel structure without the DFMDs is approximately $17.9 \mathrm{~mm}$ in Y direction, which is approximately 4 times peak displacements of the steel structure with the DFMDs. Figure 18(b) shows that the maximum displacement occurs also at the top floor and is decreased from $197 \mathrm{~mm}$ to $34 \mathrm{~mm}$. Similar results were obtained and were shown in Figure 19 and summarized in Tables 3 and 4. The reason of obvious displacement reduction is that the DXMDs contributed not only additional damping ratio the same as ordinary metallic dampers, but also additional relatively higher stiffness to the original steel structure. In addition, acceleration responses of each floor were decreased corresponding to the structure without the DXMDs because of its additional damping effect. However, the acceleration and base shear of the structure with the DXMDs are amplified under small earthquake due to obvious additional stiffness from the dampers. More attentions should be paid during seismic design. 
Table 3. Responses of the Structure in Y Direction under 1\# Record (unit: mm)

\begin{tabular}{|c|c|c|c|c|c|c|c|c|}
\hline \multirow{2}{*}{ Displacement Response } & \multicolumn{8}{|c|}{ Floor } \\
\cline { 2 - 9 } & 1 & 2 & 3 & 4 & 5 & 6 & 7 & 8 \\
\hline $\begin{array}{c}\text { Max inter-story displacement } \\
\text { (without DFMDs) }\end{array}$ & 17.9 & 47.6 & 78.8 & 100.8 & 132.0 & 152.2 & 166.0 & 196.5 \\
\hline $\begin{array}{c}\text { Max inter-story displacement } \\
\text { (with DFMDs) }\end{array}$ & 4.3 & 9.8 & 15.0 & 19.7 & 23.7 & 26.7 & 28.7 & 33.7 \\
\hline
\end{tabular}

Table 4. Responses of the Structure in Y Direction under 2\# Record (unit: mm)

\begin{tabular}{|c|c|c|c|c|c|c|c|c|}
\hline \multirow{2}{*}{ Displacement Response } & \multicolumn{8}{|c|}{ Floor } \\
\cline { 2 - 9 } & 1 & 2 & 3 & 4 & 5 & 6 & 7 & 8 \\
\hline $\begin{array}{c}\text { Max inter-story displacement } \\
\text { (without DFMDs) }\end{array}$ & 13.3 & 34.2 & 55.0 & 73.6 & 89.0 & 101.2 & 108.3 & 120.0 \\
\hline $\begin{array}{c}\text { Max inter-story displacement } \\
\text { (with DFMDs) }\end{array}$ & 3.1 & 7.3 & 11.1 & 14.5 & 17.4 & 19.6 & 21.2 & 25.0 \\
\hline
\end{tabular}

\section{SUMMARY AND CONCLUSIONS}

A new type of metallic damper is proposed in this study. Its stiffness was improved greatly relative to conventional metallic damper through it bearing in-plane exterior force, and its deformation and energy-dissipating capabilities are enhanced through making it various geometric shapes. Scaled model and full-scaled model test are carried out, respectively. Two outstanding metallic dampers named as RHMD and DXMD are selected, and the DXMD was applied in an actual steel structure. Some conclusions and suggestions are presented as follows:

(1) The steel plate shape has an important influence on deformation and energy-dissipating capability of the metallic damper;

(2) The RHMD and the DXMD exhibit good performance on stiffness and energy dissipation;

(3) The dynamic analysis of the steel structure revealed that the DXMD presented in this study reduced the displacement response effectively.

(4) The acceleration response of the structure with the DXMD or RHMD is amplified corresponding to original structure under normal use and small earthquake, so more attention must be focused on the issue during elastic seismic design;

(5) The ratio of the height and width of these two dampers equals and less than 1.0 is suggested, because relatively larger ratio probably results in out-plane buckling of the damper;

(6) Yield displacement and yield strength of these two dampers as basic parameters have directly influence on controlling displacement response.

\section{ACKNOWLEDGEMENTS}

Funding for authors was provided by the Science Fund for Creative Research Groups of the National Natural Science Foundation of China (Grant No. 51121005).

\section{REFERENCES}

[1] Lackner, M.A. and Rotea, M.A., "Passive Structural Control of Offshore Wind Turbines", Wind Energy, 2011, Vol. 14, No. 3, pp. 373-388.

[2] Housner, G.W., Bergman, L.A. and Caughey, T.K., et al. "Structural Control: Past, Present and Future”, ASCE Journal of Engineering Mechanics, 1997, Vol. 123, No. 8, pp. 897-972. 
[3] Li, H.N., Yin, Y.W. and Wang, S.Y., "Studies on Seismic Reduction of Story-increased Buildings with Friction Layer and Energy-dissipated Devices”, Earthquake Engineering \& Structural Dynamics, 2003, Vol. 32, No. 14, pp. 2143-2160.

[4] Tnanka, T., Makii, K., Ueda, H. and Kushibe, A., etc., "Study on Practical Application of a New Seismic Damper Using a Zn-Al Alloy with a Nanocrystalline Microstructure", Mechanical Sciences, 2003, Vol. 45, pp. 1599-1612.

[5] Kelly, J.M., Skinner, R.I. and Heine, A.J., "Mechanisms of Energy Absorption in Special Devices for Use in Earthquake-resistant Structures”, Bull. N.Z. National Society for Earthquake Engineering, 1972, Vol. 5, No. 3, pp. 63-88.

[6] Whittaker, A.S., Bertero, V.V., Thompson, C.I. and Alsonson, L.J., "Seismic Testing of Steel Plate Energy Dissipation Devices”, Earthquake Spectra, 1991, Vol. 7, No. 4, pp. 563-604.

[7] Tsai, K.C., Chen, H.W., Hong, C.P. and Su, Y.F., "Design of Steel Triangular Plate Energy Absorbers for Seismic Resistant Construction”, Earthquake Spectra, 1993, Vol. 19, No. 3, pp. 505-528.

[8] Skinner, R.I., Kelly, I.M., Heine, A.J and Robinson, W.H., "Hysteresis Dampers for the Protection for the Protection of Structures from Earthquake". Bull. N.Z. Nat. Soc. for Earthquake Engineering, 1980, Vol. 13, No. 1, pp. 22-26.

[9] Martinesz-Romero, E., "Experiences on the Use of Supplemental Energy Dissipators on Building Structures”, Earthquake Spectra, 1993, Vol. 9, No. 3, pp. 581-624.

[10] Bartera, F., Giacchetti, R., "Steel Dissipating Braces for Upgrading Existing Building Frames”, Journal of Constructional Steel Research, 2004, Vol. 60, pp. 751-769.

[11] Mualla, I.H., Belev, B., "Performance of Steel Frames with a New Friction Damper Device under Earthquake Excitation”, Engineering Structures, 2002, Vol. 24, pp. 365-371.

[12] Min, K.W., Kim, J., Lee, S.H., "Vibration Tests of 5-story Steel Frame with Viscoelastic Dampers”, Engineering Structures, 2004, Vol. 26, pp. 831-839.

[13] Phocas, M.C., Pocanschi, A., "Steel Frames with Bracing Mechanism and Hysteretic Dampers”, Earthquake Engineering and Structural Dynamics, 2003, Vol. 32, pp. 811-825.

[14] Moreschi, L.M., Singh, M.P., "Design of Yielding Metallic and Friction Dampers for Optimal Seismic Performance”, Earthquake Engineering and Structural Dynamics, 2003, Vol. 32, pp. 1291-1311.

[15] Curadelli, R.O., Riera, J.D., "Reliability Based Assessment of the Effectiveness of Metallic Dampers in Buildings under Seismic Excitations”, Engineering Structures, 2004, Vol. 26, pp.1931-1938.

[16] Seismic Design Code for Buildings (GB 50011 - 2001). China Architectural Industry Press, Beijing, 2001.

[17] Lin, Y.Y., Tsai, M.H., Hwang, J.S. and Chang, C.K., "Direct Displacement-based Design for Building with Passive Energy Dissipation Systems”, Engineering Structures, 2003, Vol.25, pp. 25-37.

[18] Singh, M.P., Moreschi, L.M., “Optimal Placement of Dampers for Passive Response Control”, Earthquake Engineering and Structural Dynamics, 2002, Vol. 31, pp. 955-976.

[19] Soong, T.T., Dargush, G.F., Passive Energy Dissipation Systems in Structural Engineering, John Weley \& Sons, 1997.

[20] Tehranizadeh, M. "Passive Energy Dissipation Device for Typical Steel Frame Building in Iran”, Engineering Structures, 2001, Vol. 23, No. 6, pp. 643-655.

[21] Zhang, R.H., Soong, T.T., "Seismic Design of Viscoelastic Dampers for Structural Applications”, ASCE Journal of Structural Engineering, 1992, Vol. 118, No. 5, pp.1375-1392. 